\title{
App design for teaching academic English vocabulary using spaced repetition method
}

\section{Diseño de aplicación para la enseñanza de vocabulario académico Inglés utilizando el método de repetición espaciada}

\author{
MARTÍNEZ-VALENCIA, Ricardo Fabrizio*†, MONTERO-VALVERDE, José Antonio, MARTÍNEZ- \\ ARROYO, Miriam and HERNÁNDEZ-BRAVO, Juan Miguel
}

Tecnológico Nacional de México campus Acapulco

ID $1^{\text {st }}$ Author: Ricardo Fabrizio, Martínez-Valencia / ORC ID: 0000-0003-3231-1981, CVU CONACYT ID: 800424

ID $1^{\text {st }}$ Co-author: José Antonio, Montero-Valverde / ORC ID: 0000-0001-8452-7333

ID $2^{\text {nd }}$ Co-author: Miriam, Martínez-Arroyo / ORC ID: 0000-0002-5685-1731

ID $3^{\text {rd }}$ Co-author: Juan Miguel, Hernández-Bravo / ORC ID: 0000-0003-4892-3368

DOI: $10.35429 /$ JOCT.2021.15.5.11.20

Received March 15, 2021; Accepted June 30, 2021

\begin{abstract}
In this paper, it is presented a proposal of app for teaching English vocabulary oriented to computer science field, using a spaced repetition method based on SuperMemo 2 (SM-2) algorithm, which allows reinforce the vocabulary acquired in previous studies, and dynamically generate a plan for learning the most appropriated words according to an easiness factor and word practice time interval. Also, an assessment instrument is presented, which can be used for demonstrating the acceptance of the technology throughout measuring use attitude to proposed app and usefulness perception from users. Through this learning way, students from many educational institutions can achieve a better vocabulary retention, which carries to having a better comprehension of academic texts that are required for acquiring more knowledge in their study fields.
\end{abstract}

Academic english vocabulary, Spaced repetition, Technology acceptance model

\begin{abstract}
Resumen
En este trabajo, se presenta una propuesta de aplicación para la enseñanza de vocabulario inglés orientado al área de las ciencias computacionales, utilizando un método de enseñanza por repetición espaciada basado en el algoritmo SuperMemo 2 (SM-2), el cual, permite reforzar el aprendizaje de vocabulario estudiado previamente, y planear de manera dinámica las palabras más apropiadas a aprender en función de un factor de facilidad y el intervalo de tiempo en que estas se practican. También, se presenta un instrumento de evaluación con el cual se puede comprobar la aceptación de la tecnología a través de la medición de la actitud hacia el uso de la aplicación propuesta y la percepción de la utilidad de la misma por parte de los usuarios. A través de esta forma de aprendizaje se puede lograr que los estudiantes de instituciones educativas tengan una mayor retención de las palabras que aprenden, lo que conlleva a que tengan una mayor comprensión de los textos académicos que se requieren para adquirir mayores conocimientos en sus áreas de estudio.
\end{abstract}

Vocabulario académico inglés, Repetición espaciada, Modelo de aceptación de la tecnología

Citation: MARTÍNEZ-VALENCIA, Ricardo Fabrizio, MONTERO-VALVERDE, José Antonio, MARTÍNEZ-ARROYO, Miriam and HERNÁNDEZ-BRAVO, Juan Miguel. App design for teaching academic English vocabulary using spaced repetition method. Journal of Computational Technologies. 2021. 5-15:11-20

\footnotetext{
* Author Correspondence: (e-mail: ricardofabriziomv@gmail.com)

$\dagger$ Researcher contributing as first author.
} 


\section{Introduction}

There is a strong relationship between proficiency of the English language and the competitiveness of a country. A high level of proficiency of this language translates into growth in all areas, mainly in the economy, innovation and the general well-being of inhabitants (IMCO, 2015).

In Mexico, population has difficulties for learning English. It is not only the fact of the low level, but also that it is decreasing year after year, compromising the level of competitiveness of the country.

This is reflected in the results of the Education First English Proficiency Index or EF EPI, where Mexico ranked 44th out of 80 countries evaluated in $2017 ; 57$ th place out of 88 in 2018; 67th out of 100 in 2019; and falling to 82th out of 100 in 2020, as well as 18th out of 19 in Latin America, only above Ecuador (Education First, 2020).

This situation is not only specific to Mexico. It is known that other countries present similar situations that are caused by different problems, such as low concentration on studying (Zou, 2019), lack of variety of teaching methods (Boyinbode and Tiamiyu, 2020), low learning autonomy by students (Chen and others, 2019), difficulty of comprehension and acquisition of vocabulary (Saragih, 2019), among others.

It is worth mentioning that EF EPI, as well as many other studies, have as a target population to high school and university students. Therefore, it is important to take into account, in addition to their general proficiency of the language, a sufficient proficiency of academic vocabulary, so that they are able to understand and use english academic resources in their study areas, that encourage them to acquire more knowledge and improve their professional skills.

But, as with general English, academic English also presents some learning obstacles for students. Some of these are the lack of motivation due to the use of traditional teaching techniques and equipment, the lack of inclusion of technology, and teaching not focused on the students' areas of interest (Farook and Mohamed, 2020).
In this sense, it is essential to generate proposals that integrate innovation factors and content personalization to increase the level of interest and motivation to learn the language.

LEVO APP is a proposal of a Progressive Web App or PWA, that can help to students on learning English according to their academic areas, using a spaced repetition algorithm and a word identification activity based on flashcards.

In the proposed design, it is used the Academic Vocabulary List or AVL proposed by Roesler (2020), which is oriented to the area of Computational Sciences, and, implemented as a teaching method, the spaced repetition algorithm called SuperMemo 2 (SM-2).

The intention of using this app is to obtain a positive impact on the attitude and intentionality of learning English academic vocabulary by students in the area of computer science.

As part of the content of this document, some related works referring to the use of technology for the teaching of English vocabulary are mentioned.

It is briefly addressed the academic vocabulary lists used for teaching English focused on academic areas, describing their characteristics and the benefits of their use. The SuperMemo 2 algorithm is also briefly described, as well as its interaction with vocabulary teaching process using flashcards.

Finally, it is explained the Technology Acceptance Model, which can be used for evaluating the attitude and intentionality of use of the proposed app.

\section{Teaching English: Use of Technology and Academic Vocabulary}

It is not surprising that a large number of projects related to English language teaching have been proposed for several years.

There is a general interest in offering to students the possibility of learning a language for getting professional advantages. Various approaches have been taken with the only aim of covering as many forms of teaching, and one of these is the use of technology. 
It is known that the use of computer technologies has beneficial effects on learning a new language. For example, Yip and Kwan (2006) found that there is more preference in learning English vocabulary through the use of web applications, than learning on a face-to-face method with a teacher. Furthermore, those who use technological tools for learning English have a broader vocabulary and retain words for a longer time, unlike those who only learn with traditional methods in the classroom.

Basoglu and Akdemir (2010), identified that students who use mobile applications to learn a language, spend more time studying it, and at the same time, they perceive greater entertainment in the process.

Two things can be inferred from this, first, that both web technologies and mobile technologies allow increasing proficiency with English vocabulary; and second, that both influence the perception of greater utility against conventional methods, which facilitates the process while providing greater motivation and entertainment to students.

It is worth mentioning that nowadays it is possible of combining web technologies with mobile technologies, using Progressive Web Apps, which are web applications that integrate the characteristics of a native mobile app.

These kinds of apps can be installed in users' devices, using a minimum amount of space, which leads to a saving in the amount of available storage. They can also make use of some hardware interfaces from devices, work without internet connection, and receive notifications in real time (Tandel and Jamadar, 2018). Given the proven benefits of web and mobile technologies, progressive web apps are a good technology option for using on language teaching.

In addition to the use of technological tools, another factor that positively influences the learning of English is the personalization of contents according to students' topics of interest, since this provides greater motivation for them to acquire more knowledge (Manyak and Bauer, 2009).
Kohnke et al. (2020) found that it is possible to improve vocabulary retention, implementing within apps the process of teaching by disciplines, that is, grouping words related to students' academic areas of interest.

Various research works have been carried out. The objective is to find English word lists oriented to academic areas, for offering personalized and relevant content for students, and thus, help them improve their learning (Coxhead, 2000).

Roesler (2020), mentions that knowledge of academic vocabulary is vital for reading comprehension and academic success of those who aspire to access higher-level educational systems, where the correct interpretation of technical content related to a specific area is required.

Based on this, it can be identified the relevance of generating proposals of English teaching tools that use web and mobile technologies, mainly focusing on teaching content oriented to students' areas of interest, which leads to positively influence their learning process.

\section{Learning with Spaced Repetition}

Spaced repetition is a learning method that consists on incrementing or decreasing the time a person must practice again a previously studied resource, according to the retention level the person has at the time (Schroeder, 2017).

This method has proven to be very effective for learning vocabulary of a second language, both for traditional teaching methods (Schuetze, 2017; Namaziandost and others, 2019; Nakata and Elgort, 2021), as well as for the use of technological teaching language tools (Settles and Meeder, 2016; Altiner, 2019; Kohnke and others, 2019; Seibert and Brown, 2020).

Wozniak (1990) proposed a spaced repetition algorithm called SuperMemo, for teaching through the use of flashcards. In this, the calculation of inter-repetition intervals is carried out to review the content of cards on specific days. 
The most popular version of this algorithm is version 2 (SM-2), which, in addition to calculating repetition intervals, integrates an easiness factor that helps to dynamically assign the backward or forward of the practice times of the cards, according to user responses.

The algorithm begins with the assignment of the first card repetition interval which is a oneday interval, the second a six-days interval, and since the third, the interval is calculated taking into account the previous value multiplied by the easiness factor or EF. This is determined by the pseudocode in Figure 1.

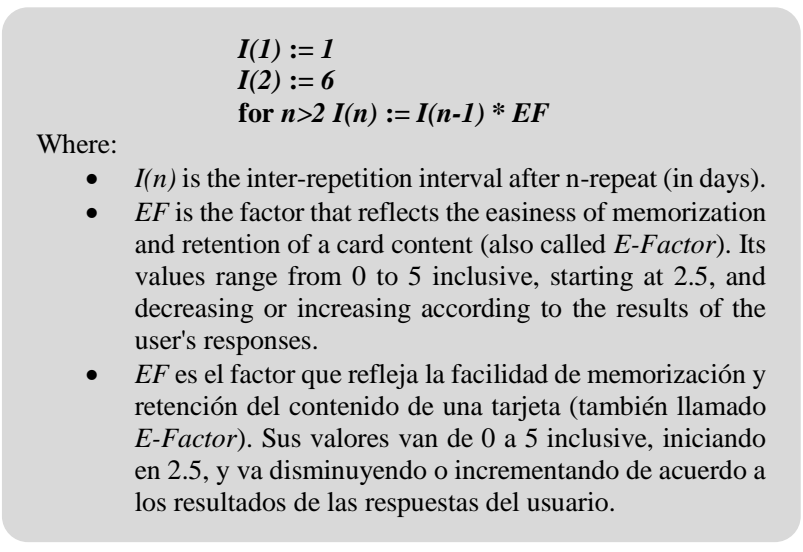

Figure 1 Calculation of inter-repetition intervals in the SM-2 algorithm (Wozniak, 1990)

Each new EF value is calculated by:

$$
E F^{\prime}=f(E F, q)
$$

Where:

$E F$ ' is the new value of E-Factor.

$E F$ is the previous value of E-Factor.

$q$ is the response quality.

$f(E F, q)$ is the calculation function of $E F$ '.

The calculation function of $E F^{\prime}$ is determined by:

$$
f(E F, q)=E F-0.8+0.28 * q-0.02 * q * q
$$

The value of $q$ is obtained from scalar values ranging from 0 to 5 (the higher, the better quality) which represent the qualitative level of response quality, and is classified based on the following criteria:

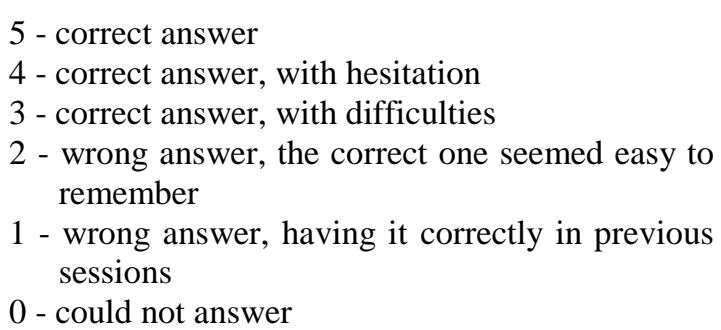

With all the values and calculations established, the SM-2 algorithm can be applied according to the steps in Figure 2.

1) Assign an $E F$ value of 2.5 to all cards.

2) Practice the cards by setting an inter-repetition interval using the steps in Figure 1.

3) After each repetition, rate the quality of the response on a scale of 0 to 5 .

4) After each repetition, and before calculating the new interval, modify the $E F$ value of the current card practiced using Equation 1. If $E F^{\prime}$ is less than 1.3, assign $E F^{\prime}=1.3$.

5) If response quality of $q$ was less than 3, then reset the repeat interval to 1, without changing the $E F$ value (use the intervals $I(1), I(2)$, etc., as if the card had not been practiced)

6) After each session on a given day, repeat all the cards with a quality value $q$ less than 4 . Continue the repetitions until all the cards have a score of at least 4 .

Figure 2 SM-2 algorithm execution (Wozniak, 1990)

\section{Technology Acceptance Model}

The main goal of developing software systems and apps is to provide tools that facilitate people's activities, in work, academic, or other kind of environments.

However, not all technology created is always well received by users, and there are two main traits that determine this: usefulness perception and ease-of-use perception.

If users perceive a technology is difficult to use and it is also not so useful for their purposes, they simply tend to have a negative attitude towards it, which translates into little or no use of the tool, and the loss of the potential benefits that can be obtained by making use of it.

The Technology Acceptance Model or TAM, is a model that evaluates the behavioral response to a technological tool (see Figure 3). According to Davis (1989) this answer is obtained by the following flow: 
- Using a technological tool generates an external stimulus in the users, according to design characteristics of it.

- This stimulus results in a cognitive response, in which the users perceive the ease-of-use level, as well as the usefulness to achieve their objectives.

- These perceptions determine an affective response towards the tool, where a positive or negative attitude is obtained for its use.

- Which finally affects the behavioral response that is reflected in the actual use of the tool.

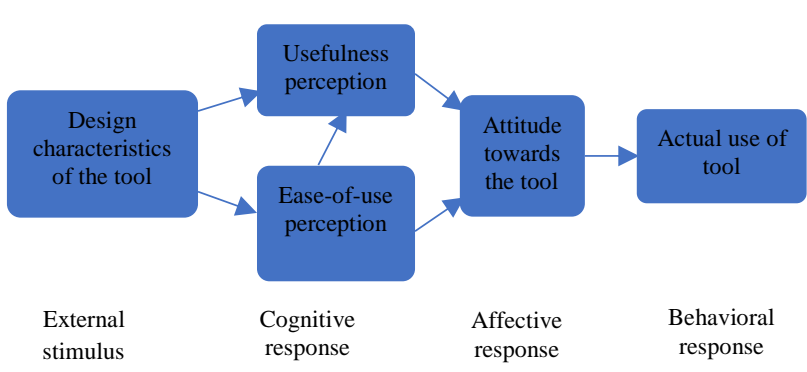

Figure 3 Technology Acceptance Model (Davis, 1989, p.3)

Venkatesh and Davis (2000) identified that the characteristics of the tools are not the only factor that determines user perceptions, but these are also affected by:

- Subjective norms. Which refers to the influence of the user's perception by external factors.

- Voluntariness. It indicates the attitude of the person to use the tool because he wishes to do so, without being forced by external factors.

- Experience. The ease-of-use that user perceives when using the tool, obtaining a good or bad experience at the end.

- Image. The way in which the user perceives that the use of the tool will give him greater status or recognition.

- Job relevance. The benefits that the user thinks they can obtain to improve the productivity, effectiveness and quality of their work by using the tool.

- $\quad$ Output quality. That refers to the quality of the information offered by the tool, and that the user can use for their specific purposes.

Result demonstrability. The ease in how the user understands the benefits of using the system and the capacity to explain it.
These factors were integrated as an extension to the first TAM, forming a second version called TAM2 (see Figure 4).

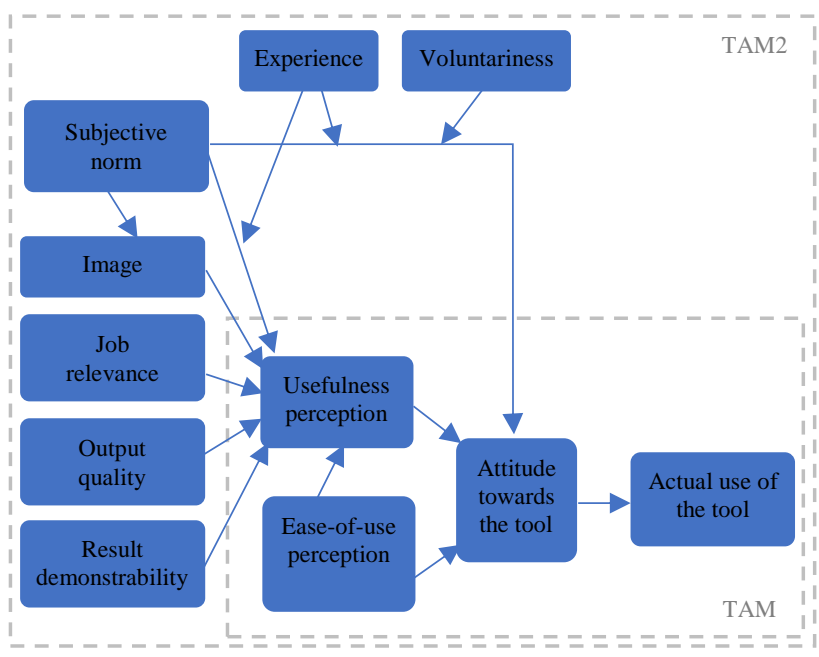

Figure 4 Technology Acceptance Model version 2 (Venkatesh y Davis, 2000, p.188)

With this version, it is possible to obtain a more precise evaluation of usefulness perception of a given technology.

It is worth mentioning that there is a third version of TAM, which includes factors that influence the ease-of-use perception, however, these are more oriented to user experience and user interfaces, which is not the main goal of the proposed app.

\section{Methodology}

The proposed app includes three stages, which are shown in Figure 5, and explained below.

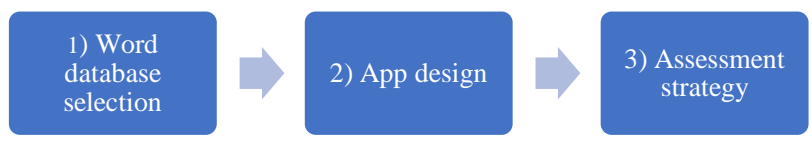

Figure 3 Stages of LEVO APP development

1) Word database selection

For the first stage, it was carried out a search of repositories that includes word lists in English categorized by academic areas. Given the extension of the number of available lists located, it was decided to take as a reference only one of these for the prototype design. 
As a reference, it is recommended to use an academic vocabulary list such as that proposed by Roesler (2020), because it is the most updated, and extends and improves the academic lists proposed by Coxhead (2000), Minshall (2013), Gardner and Davies (2014), and Lei and Liu (2016), being for this particular case, a list oriented to computer science area.

This list is made up of a main group of 904 words directly related to computer science, and a supplemental group of 702 indirectly related words, summing up 1,606 words in total.

The proposed design contemplates the use of a single vocabulary list for exemplification and testing purposes.

\section{2) App design}

It is proposed a simple design that implements a game based on flashcards, which consists of game rounds with ten words each, generated for a chosen academic area, these words are selected from inter-repetition intervals assigned to the previously practiced words. If no programmed words are found to practice, or there are not enough to complete a round of ten words, a selection is made by simple random sampling to complete the missing words of the round.

The app must present one by one, each of the ten words to the user, so that he tries to identify the translation of them, writing it in a text box. Response times are used based on the work of Schuster et al. (1990), where a 5 seconds interval is given for word analysis, and after this, a 15 seconds interval for giving an answer.

Response qualities for the SM-2 algorithm, are determined by these criteria:

- If the user answers correctly within the first 10 seconds, answer quality equals 5 .

- If a correct answer is given within 11-15 seconds, answer quality equals 4 .

- If a correct answer is given within 16-20 seconds, answer quality equals 3 .

- If the user answers incorrectly and the word's $E F$ value is below 2.5, answer quality equals 2 .

- If it is answered incorrectly a word that was correctly answered in a previous session, answer quality equals 1 .
- If 20 seconds interval ends before the user can answer, answer quality equals 0 .

For each given answer, calculation of EF value is performed, so that the easiness value of the word can be varied, and the new interrepetition interval can be established. The calculation process is repeated for each of the words, until the end of the game round. This is exemplified in Figure 6.

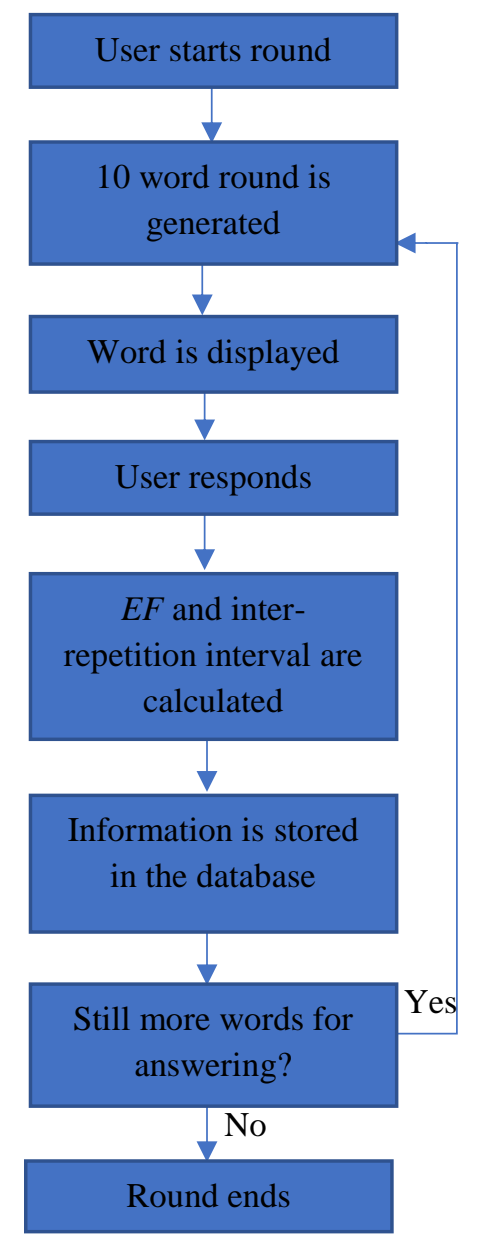

Figure 4 Word practice round process

As part of the practice process, the most relevant interface designs are presented in Figure 7. It is important to mention that is proposed a Spanish-based interface for making it easier to use by beginner-level English students.

a) Welcome screen. Where users can choose the authentication option. It is proposed to allow practicing as guests for temporarily saving the information generated, or with a registered user to keep track of the results obtained.

b) Academic area selection. Where the academic area to practice can be chosen. 
c) Practice round screen. That controls the flow of each round, includes in the upper part a sequential follow-up of the words of the round, a button to immediately restart a new round, a button to end the round, and a bar that indicates the remaining time to respond. The central part shows the word to be identified, and the text box where users can write their answers.

d) End of round. It shows a summary of the points obtained according to the quality scores obtained after each answer.

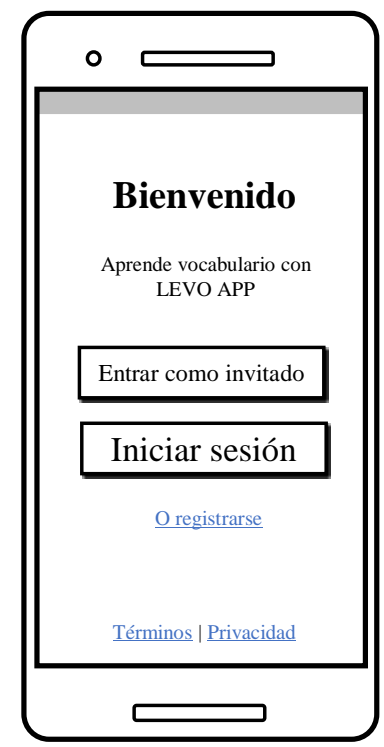

a)

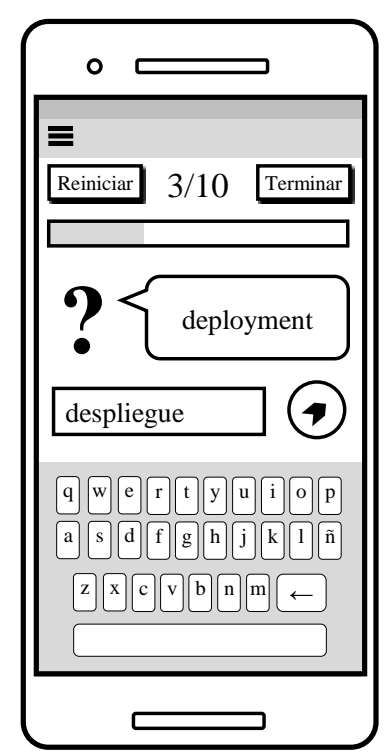

c)

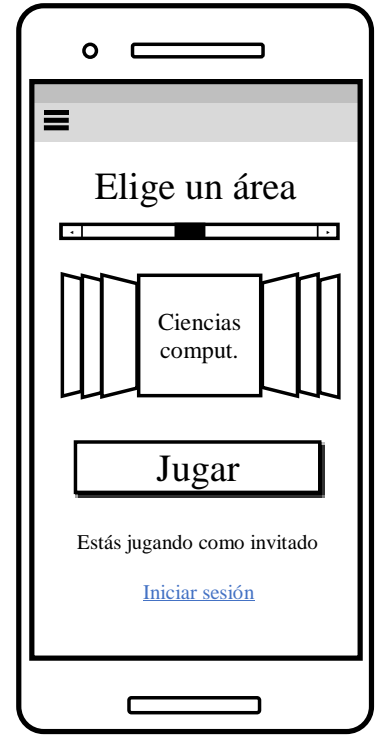

b)

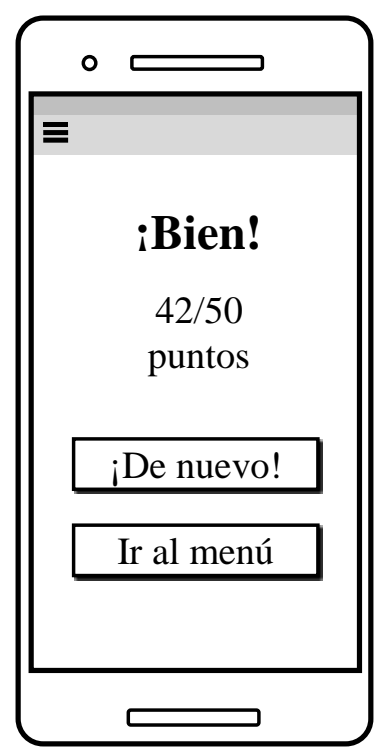

d)
Figure 5 LEVO APP user interfaces
App construction must be realized using technologies adapted for the creation of PWAs, for that reason, it has been chosen to use the MEAN development stack, composed of the MongoDB, Express.js, Angular, and Node.js technologies, since are adapted for this type of apps. Its deployment requires a web server where the application code and the database can be hosted, so a client-server architecture is more than enough to make the product available to users, requiring an internet connection to access for the first time.

\section{3) Assessment strategy}

Third stage consists of evaluating the tool through TAM2, for which, the use of an adaptation of the evaluation instrument proposed by Venkatesh and Davis (2000) is proposed, which is made up of 26 items grouped into 9 sections.

Each item presents a sentence for which users must assign a concordance value, according to their perceptions about the app.

The proposed instrument is made up of sections identified by sections (a) to (i), each one containing their respective items, as shown next:

(a) Intention to use

- Assuming I have access to the app, I intend to use it.

- Given that I have access to the system, I predict that I would use it.

(b) Perceived usefulness

- Using the app, my academic English performance will increase.

- Using the app, I will increase my productivity on academic activities that require English language.

- Using the app, I enhance my effectiveness on academic activities that require English language.

- $\quad$ I find the app to be useful in my English learning process.

(c) Perceived ease of use

- My interaction with the app is clear and understandable.

- $\quad$ Interacting with the app does not require a lot of my mental heart.

- $\quad$ I find the app to be easy to use.

- $\quad$ I find it easy to get the app to do what I want it to do. 
(d) Subjective norm

- People who influence my behavior think that I should use the app.

- $\quad$ People who are important to me think that I should use the app.

(e) Voluntariness

- My use of the app is voluntary.

- People does not require me to use the app.

- Although it might be helpful, using the app is certainly not compulsory in my academic activities.

(f) Image

- $\quad$ Students in my university who use the app have more prestige than those who do not.

- $\quad$ Students in my university who use the app have a high profile.

- Using the app is a status symbol in my university.

(g) Academic relevance

- In my academic activities, usage of the app is important

- $\quad$ In my academic activities, usage of the app is relevant.

(h) Output quality

- $\quad$ The quality of the output I get from the app is high.

- I have no problem with the quality of the app's output.

(i) Result demonstrability

- I have no difficulty telling others about the results of using the app.

- I believe I could communicate to others the consequences of using the app.

- $\quad$ The results of using the app are apparent to me.

- I would have difficulty explaining why using the system may or may not be beneficial.

Each item is measured by means of a scale that goes from zero to seven, which represent the following qualitative values:

$1=$ Strongly disagree

$2=$ Mostly disagree

$3=$ A little disagree

$4=$ Neutral (neither agree nor disagree)

$5=$ A little agree

$6=$ Mostly agree

\section{$7=$ Strongly agree}

The data set obtained can be modeled with a software tool such as SmartPLS to obtain the values for making a comparison and identify if there is a positive intention of using the proposed app.

\section{Results}

The proposed design, being based on elements whose benefits have been proven, allows identifying the results that can be obtained once it is implemented:

- Being a PWA, LEVO APP provides the benefits of this type of app, such as access from almost any device with an internet connection, security, responsive interface, operation without connectivity or low quality of internet connection, native mobile app behavior, continuous updating, small size and ease of installation (Tandel and Jamadar, 2018; Mhaske and others, 2018), in addition to serving as a form of encouragement and motivation, unlike traditional teaching methods.

- $\quad$ The use of flashcards for learning English vocabulary is very extensive, due to its simplicity, and in conjunction with a spaced repetition teaching method such as SM-2, greater data retention can be achieved, of around $90 \%$ of the information practiced (Wozniak, 1990).

- The use of a vocabulary personalized to the interests of the users, in this case, to academic areas, positively influences the retention of the words that are practiced.

From the above, it can be inferred that, by implementing these characteristics, a positive attitude can be obtained towards the use of the app, for learning academic English vocabulary.

\section{Conclusions}

English language proficiency is very relevant for the competitiveness of a country. Much of the learning of this language occurs in high school and university, and, it is at this time when students must have good proficiency of it, to be able to understand academic information that entails to learn more about the chosen academic area.

MARTÍNEZ-VALENCIA, Ricardo Fabrizio, MONTERO-VALVERDE, José Antonio, MARTÍNEZ-ARROYO, Miriam and HERNÁNDEZBRAVO, Juan Miguel. App design for teaching academic English vocabulary using spaced repetition method. Journal of Computational Technologies. 202 
Although there are apps for teaching English vocabulary, many of these focus on a general vocabulary, which, although it is of great importance to provide the foundations of a more advanced vocabulary, it is also necessary to have proposals that focus into a higher level of specialization, useful for people who study a certain area and who can generate more knowledge in the field. Also, the importance of using methodologies that help in a better way to retain the vocabulary learned is identified, without forcing the rigid memorization of words.

Spaced repetition method shows to be an effective gradual teaching method, which, combined with current technologies such as progressive web apps and simple teaching methodologies such as flashcards, generate solutions that are liked by users, which has a direct impact in their attitude towards the use of them and the perception of usefulness for their academic purposes.

\section{Acknowledgements}

To Consejo Nacional de Ciencia y Tecnología (CONACYT) for the financial support for the realization of this project, and to Tecnológico Nacional de México campus Acapulco for the infrastructure and technology facilities provided.

\section{References}

Altiner, C. (2019). Integrating a ComputerBased Flashcard Program into Academic Vocabulary Learning. Turkish Online Journal of Educational Technology-TOJET, 18(1), 44-62.

Arnold, B. A. (2019). The seven traits of a learning environment: a framework for evaluating mobile learning engagement. Int. J. E-Education, e-Business, e-Management eLearning, 9, 54-60.

Basoglu, E. B., y Akdemir, O. (2010). A comparison of undergraduate students' English vocabulary learning: Using mobile phones and flash cards. Turkish Online Journal of Educational Technology-TOJET, 9(3), 1-7.

Boyinbode, O., y Tiamiyu, A. (2020). A Mobile Gamification English Vocabulary Learning System for Motivating English Learning. IOSR Journal of Mobile Computing \& Application (IOSR-JMCA), 7(2), 14-29.
Chen, C. M., Chen, L. C., y Yang, S. M. (2019). An English vocabulary learning app with selfregulated learning mechanism to improve learning performance and motivation. Computer Assisted Language Learning, 32(3), 237-260.

Coxhead, A. (2000). A new academic word list. TESOL quarterly, 34(2), 213-238.

Davis, F. D. (1989). Technology Acceptance Model: TAM. Al-Suqri, MN, Al-Aufi, AS: Information Seeking Behavior and Technology Adoption, S, 205-219.

Education First. (2020). EF English Proficiency Index. Education First.

Farook, A. H. A., y Mohamed, R. N. G. (2020). Students' Lack of Interest in Learning GCE Advanced Level (A/L) General English: Factors and Remedies. A Survey Research Based on GCE Advanced Level Students of T/Mu/Al Hilal Central College, Mutur, Trincomalee, Sri Lanka. American Scientific Research Journal for Engineering, Technology, and Sciences (ASRJETS), 71(1), 174-181.

Goossens, N. A., Camp, G., Verkoeijen, P. P., Tabbers, H. K., y Zwaan, R. A. (2012). Spreading the words: A spacing effect in vocabulary learning. Journal of Cognitive Psychology, 24(8), 965-971.

Instituto Mexicano para la Competitividad. (2015). Inglés es Posible. Propuesta de una Agenda Nacional. IMCO.

Kohnke, L., Zhang, R., y Zou, D. (2019). Using mobile vocabulary learning apps as aids to knowledge retention: Business vocabulary acquisition. Journal of Asia TEFL, 16(2), 683.

Kohnke, L., Zou, D., y Zhang, R. (2020). Exploring Discipline-Specific Vocabulary Retention in L2 through App Design: Implications for Higher Education Students. RELC Journal, 0033688219899740.

Manyak, P. C., y Bauer, E. B. (2009). English vocabulary instruction for English learners. The Reading Teacher, 63(2), 174-176.

Mhaske, A., Bhattad, A., Khamkar, P., y More, R. (2018). Progressive Web App for Educational System. International Research Journal of Engineering and Technology (IRJET), 5(1). 
Nakata, T., y Elgort, I. (2021). Effects of spacing on contextual vocabulary learning: Spacing facilitates the acquisition of explicit, but not tacit, vocabulary knowledge. Second Language Research, 37(2), 233-260.

Namaziandost, E., Nasri, M., Esfahani, F. R., Keshmirshekan, M. H., y Agudo, J. D. D. M. (2019). The impacts of spaced and massed distribution instruction on EFL learners' vocabulary learning. Cogent Education, 6(1), 1661131.

Roesler, D. (2020). A Computer Science Academic Vocabulary List. Portland State University Library.

Saragih, E. (2019). The effect of semantic mapping technique on technical vocabulary mastery for Midwifery students. Studies in English Language and Education, 6(2), 333342 .

Schroeder, J. (2017). Advanced persistent training: Take your security awareness program to the next level. Apress.

Schuetze, U. (2017). Efficiency in second language vocabulary learning. Die Unterrichtspraxis/Teaching German, 50(1), 2231.

Schuster, J. W., Stevens, K. B., \& Doak, P. K. (1990). Using constant time delay to teach word definitions. The Journal of Special Education, 24(3), 306-318.

Seibert Hanson, A. E., y Brown, C. M. (2020). Enhancing L2 learning through a mobile assisted spaced-repetition tool: an effective but bitter pill?. Computer Assisted Language Learning, 33(1-2), 133-155.

Settles, B., y Meeder, B. (2016). A trainable spaced repetition model for language learning. In Proceedings of the 54th annual meeting of the association for computational linguistics (volume 1: long papers) (pp. 1848-1858).

Tandel, S. S., y Jamadar, A. (2018). Impact of progressive web apps on web app development. International Journal of Innovative Research in Science, Engineering and Technology, 7(9), 9439-9444.
Venkatesh, V., y Davis, F. D. (2000). A theoretical extension of the technology acceptance model: Four longitudinal field studies. Management science, 46(2), 186-204.

Wozniak, P. A., y Gorzelanczyk, E. J. (1994). Optimization of repetition spacing in the practice of learning. Acta neurobiologiae experimentalis, $54,59-59$.

Wozniak, P. (1990). Application of a computer to improve the results obtained in working with the SuperMemo method. Tomado de: https://www.supermemo.com/en/archives19902015/english/ol/sm2.

Yip, F. W., y Kwan, A. C. (2006). Online vocabulary games as a tool for teaching and learning English vocabulary. Educational media international, 43(3), 233-249.

Zou, D., Huang, Y., y Xie, H. (2019). Digital game-based vocabulary learning: where are we and where are we going?. Computer Assisted Language Learning, 1-27. 